Article

\title{
One-Pot Biocatalytic Preparation of Enantiopure Unusual $\alpha$-Amino Acids from $\alpha$-Hydroxy Acids via a Hydrogen-Borrowing Dual-Enzyme Cascade
}

\author{
Fei Liu ${ }^{\dagger}$, Junping Zhou ${ }^{\dagger}$, Meijuan Xu, Taowei Yang, Minglong Shao, Xian Zhang ${ }^{*}$ \\ and Zhiming Rao *(i) \\ The Key Laboratory of Industrial Biotechnology, Ministry of Education, School of Biotechnology, \\ Jiangnan University, Wuxi 214122, China; liufei1110@outlook.com (F.L.); zhoujp116@sina.com (J.Z.); \\ xumeijuan@jiangnan.edu.cn (M.X.); yangtw@jiangnan.edu.cn (T.Y.); mlshao@jiangnan.edu.cn (M.S.) \\ * Correspondence: zx@jiangnan.edu.cn (X.Z.); raozhm@jiangnan.edu.cn (Z.R.); Tel.: +86-0510-85916881 (Z.R.); \\ Fax: +86-0510-85918516 (Z.R.) \\ + Authors contributed equally to this study.
}

Received: 15 November 2020; Accepted: 12 December 2020; Published: 16 December 2020

\begin{abstract}
Unusual $\alpha$-amino acids (UAAs) are important fundamental building blocks and play a key role in medicinal chemistry. Here, we constructed a hydrogen-borrowing dual-enzyme cascade for efficient synthesis of UAAs from $\alpha$-hydroxy acids ( $\alpha$-HAs). D-mandelate dehydrogenase from Lactobacillus brevis ( $L b \mathrm{MDH}$ ) was screened for the catalysis of $\alpha$-HAs to $\alpha$-keto acids but with low activity towards aliphatic $\alpha$-HAs. Therefore, we rational engineered $L b \mathrm{MDH}$ to improve its activity towards aliphatic $\alpha$-HAs. The substitution of residue Leu243 located in the substrate entrance channel with nonpolar amino acids like Met, Trp, and Ile significantly influenced the enzyme activity towards different $\alpha$-HAs. Compared with wild type (WT), variant L243W showed $103 \mathrm{U} / \mathrm{mg}$ activity towards D- $\alpha$-hydroxybutyric acid, 1.7 times of the WT's $60.2 \mathrm{U} / \mathrm{mg}$, while its activity towards D-mandelic acid decreased. Variant L243M showed 2.3 times activity towards D-mandelic acid compared to WT, and its half-life at $40{ }^{\circ} \mathrm{C}$ increased to $150.2 \mathrm{~h}$ comparing with $98.5 \mathrm{~h}$ of WT. By combining LbMDH with L-leucine dehydrogenase from Bacillus cereus, the synthesis of structurally diverse range of UAAs from $\alpha$-HAs was constructed. We achieved $90.7 \%$ conversion for L-phenylglycine production and $66.7 \%$ conversion for $\mathrm{L}-\alpha$-aminobutyric acid production. This redox self-sufficient cascade provided high catalytic efficiency and generated pure products.
\end{abstract}

Keywords: D-mandelate dehydrogenase; unusual $\alpha$-amino acids; rational engineering; site-saturation mutagenesis; hydrogen-borrowing cascade

\section{Introduction}

Unusual amino acids (UAAs) with readily functionalized amine and carboxyl groups are valuable building blocks of modern medicinal chemistry [1-3], including free amino acid drugs, anticancer agents, antimicrobial peptides, and cyclic peptide antibiotics, among others [4-7]. A large amount of drugs and biologically active molecules rely on central UAAs [8,9], such as L-phenylglycine, which has been applied in $\beta$-lactam antibiotics including penicillin and pristinamycin I [10,11], while L- $\alpha$-aminobutyric acid is an important precursor for the synthesis of many chiral drugs like brivaracetam and ethambutol [12,13]. Furthermore, UAAs also have great potential in the preparation of smart nanomaterials, for example, part of dipeptides containing norvaline can be assembled into microporous organic materials $[1,14]$. Currently, the preparation of UAAs is mainly achieved by chemical synthesis which are environmentally unfriendly and result in many byproducts $[15,16]$. Hence, it is necessary to produce UAAs by biocatalytic processes. 
One-pot biocatalytic preparation of high-value chemicals is an essential strategy, with the advantage of concise reaction, excellent enantioselectivity, and environmental friendliness [17]. In recent years, two or multi-enzyme cascade catalysis systems have been widely used in the synthesis of UAAs [18]. Li et al assembled eight enzymes for the production of aromatic $\alpha$-amino acids from original aromatic alkene substrates [19]. While the substrates are constraint to aromatic alkene, substitution of $-X$, -Me, and -OMe on benzene ring results in phenylglycine or its derivative as the products; however, this cascade system required cosubstrate $\mathrm{NAD}(\mathrm{P}) \mathrm{H}$ and substrate $\mathrm{O}_{2}$ which restricted its catalytic efficiency. It was reported that the introduction of a three-enzyme redox-neutral cascade improved production of L-phenylglycine from racemic mandelic acid, whereby the hydride liberated in the oxidation of mandelic acid to benzoylformic acid was directly consumed in the reductive amination of benzoylformic acid using NAD as a cofactor [20]. This cascade is also known as a hydrogen-borrowing cascade [21]. In addition, studies reported the use of the same cascade with some novel D-mandelate dehydrogenases for the production of L-phenylglycine with high catalytic efficiency and good enantioselectivity $[22,23]$. Therefore, it is an efficient strategy for synthesis of UAAs using D- $\alpha$-hydroxy acid (D- $\alpha-H A)$ substrates through hydrogen-borrowing cascade reactions. However, in these studies, most of the multi-enzyme cascade systems are used for the synthesis of aromatic products, and it is still a challenge for the biocatalytic preparation of other groups of UAAs like aliphatic UAAs.

Screening novel D-hydroxy acid dehydrogenases with high activity towards aliphatic D- $\alpha$-HAs is the ideal approach, however, the natural enzymes usually do not achieve high productivity, making engineering of known enzymes of prime importance. Directed evolution, rational, and semi-rational engineering are common strategies for enzymatic modification [24-27]. Compared to rational engineering, high-through screening methods need plenty of work but usually have very few positive mutations. By rational engineering and analyzing the substrate channel, Bao et al. identified residues which control the substrate chain-length selectivity of cyanobacterial aldehyde-deformylating oxygenase [28]. After structural and substrate channel analysis, Song et al. used semi-saturated mutation for expanding the substrate tunnel and obtained two mutations with 18 -fold increase in the initial reaction rate [16]. Therefore, it is an efficient strategy for changing substrate specificity by expanding or narrowing the substrate channel.

Here, we screened a NAD-dependent D-mandelate dehydrogenase from Lactobacillus brevis $(\mathrm{L} b \mathrm{MDH})$ which was identified by Fan et al. and found that its activity towards aliphatic substrates like $\mathrm{D}-\alpha$-hydroxybutyric acid was low. Thus, rational engineering of $L b \mathrm{MDH}$ was conducted by engineering the substrate entrance tunnel to improve the substrate affinities and catalytic efficiencies. Then, we introduced NADH-dependent L-leucine dehydrogenase from Bacillus cereus (BcLeuDH) to construct a hydrogen-borrowing dual-enzyme cascade system for catalyzing D- $\alpha$-HAs to L-UAAs (shown in Figure 1). As in our precious work, we found that $B c$ LeuDH could catalyze not only aromatic substrates but also aliphatic $\alpha$-keto acids [9,29], which was suitable for this cascade system. Our strategy provided an efficient strategy for biocatalytic preparation of a broad-range L-UAAs, with the enhancement of $\mathrm{LbMDH}$ activity towards aromatic and aliphatic $\alpha$-Has, contributing significantly to the biocatalytic preparation of UAAs. 


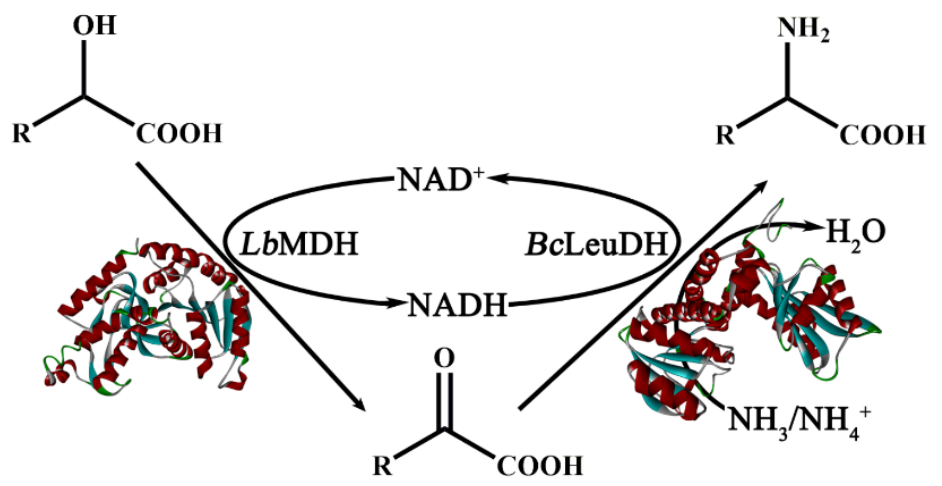

Figure 1. Scheme of the asymmetric biocatalytic preparation for UAAs from $\alpha-\mathrm{HAs}$ via a hydrogen-borrowing dual-enzyme cascade composed of L. brevis D-mandelate dehydrogenase ( $L b \mathrm{MDH})$ and Bacillus cereus L-leucine dehydrogenase (BcLeuDH).

\section{Results and Discussion}

\subsection{Expression and Comparative Enzyme Activity of D-Hydroxy Acid Dehydrogenases}

In order to find an efficient dehydrogenase that could synthesize different $\alpha$-keto acids, we screened for D-hydroxy acid dehydrogenase with high activity and broad substrate spectrum. We chose five D-hydroxy acid dehydrogenases from L. brevis, Enterococcus faecalis, Staphylococcus aureus, and Pseudomonas aeruginosa including $\mathrm{LbMDH}, \mathrm{Ef} 2 \mathrm{D} 2 \mathrm{R}, \mathrm{SaDlacDH}, \mathrm{PaDlacDH}$, and Pa2D2R using the NCBI database and expressed them in E. coli BL21 (DE3). The expression of these enzymes was analyzed by SDS-PAGE (Figure S1). The purified enzyme activities and the optimum $\mathrm{pH}$ towards substrate D-mandelic acid, D- $\alpha$-hydroxybutyrate and D- $\alpha$-hydroxycaproic acid were shown in Table 1. Interestingly, they were all alkalophilic dehydrogenases (Figure S2), and, among which, D-mandelate dehydrogenase from L. brevis exhibited higher activity with all the substrates. The $L b \mathrm{MDH}$ displayed the highest activity towards D-mandelic acid, with the specific enzyme activity of $243.54 \mathrm{U} / \mathrm{mg}$ using NAD as the cofactor. However, the activity for aliphatic substrates D- $\alpha$-hydroxybutyrate and D- $\alpha$-hydroxycaproic acid were only $24.7 \%$ and $48.8 \%$ of the activity for D-mandelic acid, respectively. Therefore, enzyme modification of $L b \mathrm{MDH}$ was necessary in order to improve the activity towards aliphatic $\alpha$-HAs.

Table 1. Comparison of enzyme activities towards D- $\alpha$-HAs of D-hydroxy acid dehydrogenase from different sources.

\begin{tabular}{ccccccc}
\hline Source & Enzyme & $\begin{array}{c}\text { D-Mandelic } \\
\text { Acid (U/mg) }\end{array}$ & $\begin{array}{c}\text { D- } \alpha \text {-Hydroxybutyric } \\
\text { Acid (U/mg) }\end{array}$ & $\begin{array}{c}\text { D- } \alpha \text {-Hydroxycaproic } \\
\text { Acid (U/mg) }\end{array}$ & Optimum pH & Cofactor \\
\hline L. brevis & LbMDH & $243.5 \pm 13.5$ & $60.2 \pm 4.7$ & $118.9 \pm 10.6$ & 10.5 \\
E. faecalis & Ef2D2R & $12.4 \pm 1.3$ & $13.2 \pm 3.9$ & $10.5 \pm 2.4$ & 10.5 & $\mathrm{NAD}^{+}$ \\
S. aureus & SaDlacDH & $6.5 \pm 0.9$ & $\mathrm{n} / \mathrm{a}$ & $\mathrm{n} / \mathrm{a}$ & 11.0 & $\mathrm{NAD}^{+}$ \\
P. aeruginosa & PaDlacDH & $0.9 \pm 0.4$ & $\mathrm{n} / \mathrm{a}$ & $\mathrm{N} / \mathrm{a}$ & $\mathrm{NAD}^{+}$ \\
P. aeruginosa & Pa2D2R & n/a & $0.7 \pm 0.2$ & $0.8 \pm 0.4$ & 11.5 & $\mathrm{NADP}^{+}$ \\
\hline
\end{tabular}

Note: n/a represented not available in this case.

\subsection{Rational Engineering of $\mathrm{LbMDH}$}

Our results indicated that the catalytic ability of $L b \mathrm{MDH}$ significantly decreased as the size of the substrate side chain decreased. Therefore, rational engineering of $L b \mathrm{MDH}$ towards aliphatic substrates with short side chains was necessary for further application. Firstly, the LbMDH homology model was constructed by SWISS-MODEL using D-mandelate dehydrogenase from E. faecium as template. Sequence alignment of $L b \mathrm{MDH}$ with other dehydrogenase from Lactobacillus harbinensi and E. faecium which had the same catalytic function (Figure S2) was then performed. To determine the residues for mutation, structural analysis between $L b \mathrm{MDH}$ and $E f \mathrm{MDH}$ was carried out (Figure 2A). Residue K186, 
corresponding to $\mathrm{K} 187$ of $E f \mathrm{MDH}$, has been considered to be conserved and as the crucial acid/base catalyst [30]. The NADH and substrate binding sites involving R268, N104, E271, N194, S259, and N190 were also conserved-among which N104 promoted the shear motion of the N-terminal domain that promotes orientation of NADH closer to the substrate by $1.7 \AA$ [31]. M128 and T130 in EfMDH comprised the entrance of the substrate binding pocket, while the corresponding sites in $L b \mathrm{MDH}$ were V127 and S129, respectively. Both two residues had smaller side chains compared with those in $E f \mathrm{MDH}$, which meant a larger pocket. With the help of structure and sequence analysis, we had a thorough understanding of the conserved active site and substrate channel of $L b \mathrm{MDH}$. In addition, it has been proved that the residues near the active pocket or substrate channel show a significant effect in enzymatic catalytic efficiency and the substrate affinity [9,32]. Thus, six residues (V127, L189, L193, I204, L243, and Q247) near the active pocket or substrate channel were chosen for site-directed mutagenesis (Figure 2B). We aimed at improving the catalytic efficiency towards aliphatic substrates by changing the steric hindrance; thus, Ala and Trp, which have shorter or bigger side chains, were both chosen for target amino acids of mutagenesis. As a result, the variants V127A, L189A, L189W, L193A, L193W, I204A, L243W, L243A, Q247A, and Q247W were constructed.
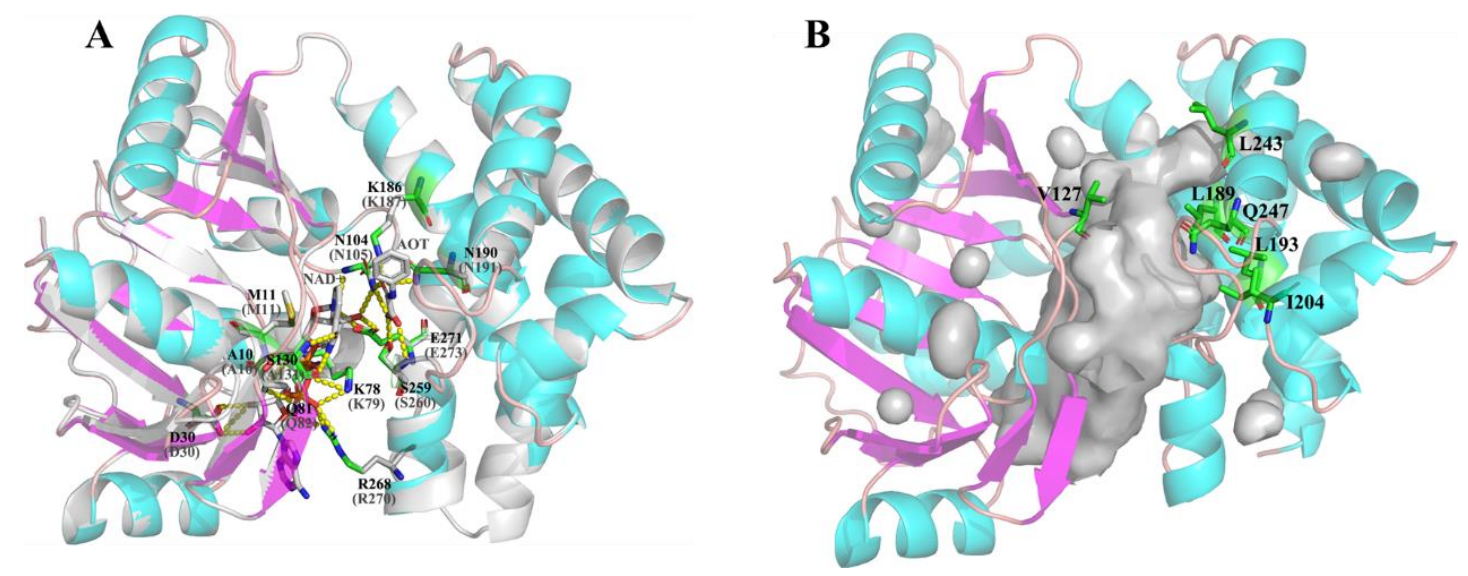

Figure 2. Structure analysis of $L b \mathrm{MDH}$. (A) structure analysis of alignment between $L b \mathrm{MDH}$ and Ef MDH (PDB ID 5X20, showed in gray). The NAD and substrate binding site of Ef MDH marked in gray and the corresponding residues of $L b \mathrm{MDH}$ marked in green were all showed as sticks with the hydrogen bonds in yellow. (B) Cavities and pockets of $L b \mathrm{MDH}$ were showed in gray, and the residues near the active pocket or substrate channel were marked in green.

After purification, the relative activities were determined using D- $\alpha$-hydroxybutyric acid and D-mandelic acid as substrates. As shown in Figure 3A, only variant L243W showed improved catalytic activity towards D- $\alpha$-hydroxybutyric acid (approximately 1.71 times compared to that of the wild type). As D-mandelic acid is the natural substrate, the enzyme activity of L243W mutation towards D-mandelic acid was measured; unfortunately, the enzyme activity towards substrate D-mandelic acid decreased by $57.9 \%$ (Figure 3B).

\subsection{Site-Saturation Mutagenesis at Residue L243}

Since the variant L243W showed different activity towards aliphatic and aromatic substrates, L243 in LbMDH was considered as a crucial residue for studying the enzyme's substrate spectrum, and the site-saturation mutagenesis was carried out at residue L243. As shown in Figure 4, the results indicated that the replacement of Leu with Phe and Trp significantly improved the activity towards D- $\alpha$-hydroxybutyric acid by $52.9 \%$ and $71 \%$, respectively. For substrate D- $\alpha$-hydroxybutyric acid, variants L243H, L243I, L243M, and L243V showed relatively similar activity as the wild type. Interestingly, the substitutions that increased or had some influence on the enzyme activities towards D- $\alpha$-hydroxybutyric acid were all hydrophobic amino acids, which meant that the hydrophobic 
environment at this position was very important for activity. Then, the substrate spectrums of $L b \mathrm{MDH}$ and the six mutations were studied (Table 2). It was found that the highest activity towards different substrates was observed in different variants; for example, the L243M variant showed the highest activity towards D-mandelic acid, which was 1.3 times higher than that of wild type, the L243W variant showed $71 \%$ increased activity towards D- $\alpha$-hydroxybutyric acid, while L243I variant had a $46.9 \%$ increase in activity towards D- $\alpha$-hydroxycaproic acid compared with wild type.
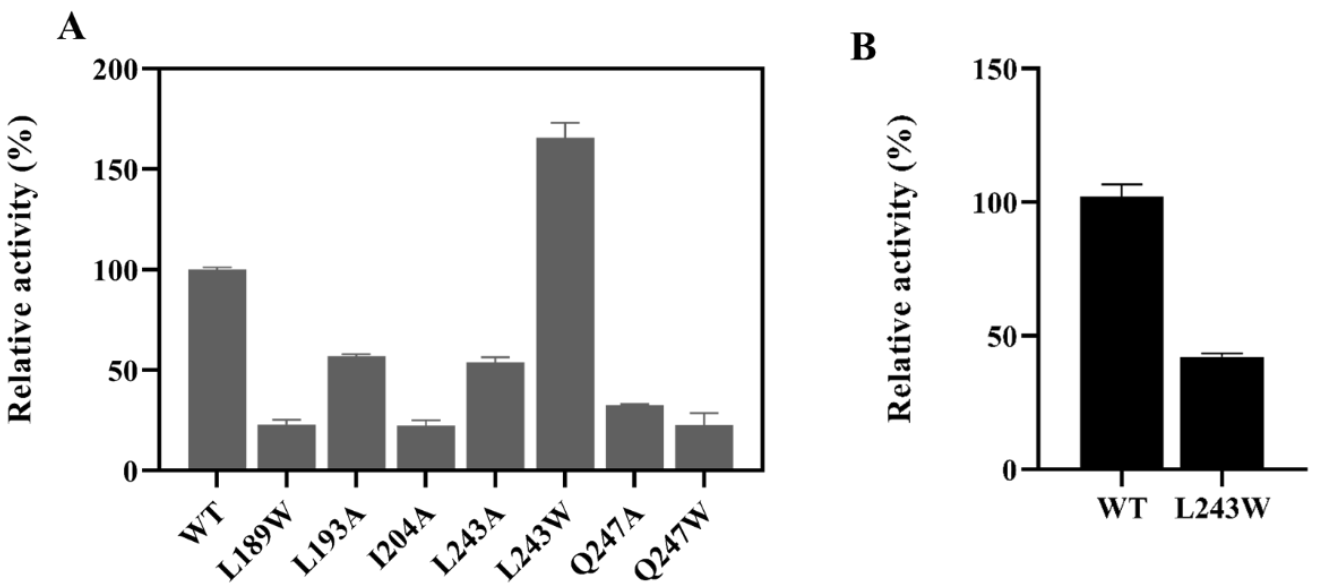

Figure 3. Screening of mutants. (A) relative activities of $L b \mathrm{MDH}$ wild type and the variants with D- $\alpha$-hydroxybutyric acid as substrate; (B) relative activities of $L b \mathrm{MDH}$ wild type and L243W variant with D-mandelic acid as substrate. The enzyme activities towards D-hydroxybutanoic acid and D-mandelic acid of wild type were 243.5 and $60.2 \mathrm{U} / \mathrm{mg}$, which were set to $100 \%$, respectively. All assays were performed in triplicate.

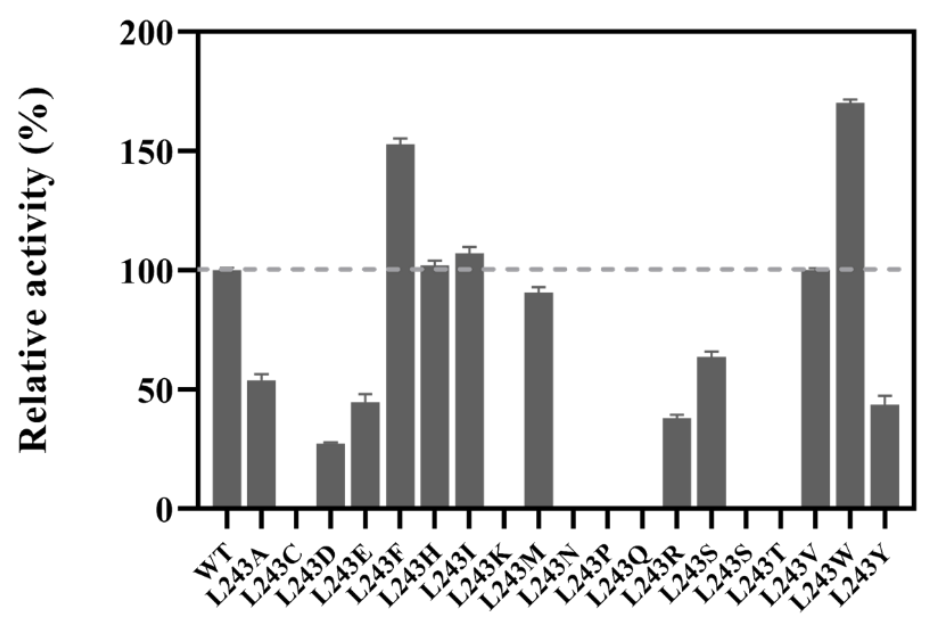

Figure 4. Enzyme activities of $L b \mathrm{MDH}$ wild type and the site-saturation mutations at L243 with D- $\alpha$-hydroxybutyric acid as the substrate.

\subsection{Enzyme Characterization and Kinetic Analysis of LbMDH and Variants}

To study the enzymatic characteristics, we used D-mandelic acid as the model substrate. As showed in Figure 5A, the optimum temperature for L243I was $35^{\circ} \mathrm{C}$, while the optimum temperature for the wild type and other variants were $40{ }^{\circ} \mathrm{C}$. Above $45^{\circ} \mathrm{C}$, the enzyme activity decreased sharply and the enzyme barely had any activity at $50{ }^{\circ} \mathrm{C}$ (Figure $5 \mathrm{~A}$ ), which indicated that the enzyme was not stable at high temperatures. The half-lives of thermal inactivation $\left(t_{1 / 2}\right)$ at $40{ }^{\circ} \mathrm{C}$ for $\mathrm{LbMDH}$ was $98.5 \mathrm{~h}$, as showed in (Figure 5B, Figure S5), while only variant L243M showed improved $t_{1 / 2}$ of about $140.2 \mathrm{~h}$ 
compared to that of the wild type-whereas, the substitution of L243W and L243I in LbMDH showed declined thermostabilities. Afterwards, the optimum $\mathrm{pH}$ of $L b \mathrm{MDH}$ and its variants were analyzed, and they all showed the highest activity under the condition of $\mathrm{pH} 10.0-11.0$ (Figure S4). For the $\mathrm{pH}$ stability experiments, all the enzymes were stored at $4{ }^{\circ} \mathrm{C}$ in $\mathrm{pH} 3.0-12.0$ buffer for $24 \mathrm{~h}$ (Figure 5C). The relative activity results revealed that the enzymes were highly stable in $\mathrm{pH}$ range $6.0-10.0$ and were unstable when the $\mathrm{pH}$ was under 4.0 or above 10.0, except for the L243W mutation which had lower residual activity compared to other variants.

Table 2. The specific activities of $L b \mathrm{MDH}$ and its variants with different D-Hydroxy acids.

\begin{tabular}{|c|c|c|c|c|c|c|c|}
\hline \multirow{2}{*}{ Substrate } & \multicolumn{7}{|c|}{ Relative Activity (\%) } \\
\hline & WT & L243M & L243W & L243V & L243I & L243F & L243H \\
\hline D-Mandelic acid & 100 & $231.2 \pm 5.6$ & $42.1 \pm 0.8$ & $169.5 \pm 6.7$ & $192.7 \pm 2.5$ & $50.8 \pm 1.9$ & $105.2 \pm 2.1$ \\
\hline D- $\alpha$-Hydroxybutanoic acid & 100 & $90.0 \pm 1.3$ & $171.0 \pm 8.1$ & $99.9 \pm 4.2$ & $107.5 \pm 5.3$ & $152.9 \pm 9.3$ & $98.3 \pm 3.0$ \\
\hline D- $\alpha$-hydroxycaproic acid & 100 & $121.6 \pm 3.7$ & $85.8 \pm 6.0$ & $130.8 \pm 7.9$ & $146.9 \pm 7.8$ & $93.7 \pm 4.1$ & $106.6 \pm 3.5$ \\
\hline D-Phenyllactic acid & 100 & $78.5 \pm 4.3$ & $79.7 \pm 3.2$ & $67.0 \pm 4.8$ & $138.8 \pm 9.2$ & $81.4 \pm 3.9$ & $92.8 \pm 6.2$ \\
\hline D-Lactic acid & 100 & $92.6 \pm 8.9$ & $339.1 \pm 15.9$ & $126.3 \pm 6.3$ & $75.9 \pm 4.4$ & $424.2 \pm 29.7$ & $130.5 \pm 5.0$ \\
\hline
\end{tabular}

Note: The enzyme activity of WT for different substrates was considered to be $100 \%$. The enzyme activity of WT for D-mandelic acid, D- $\alpha$-hydroxybutanoic acid, D- $\alpha$-hydroxycaproic acid, D-phenyllactic acid, and D-lactic are 243.5, $60.2,118.9,26.2,1.4 \mathrm{U} / \mathrm{mg}$.
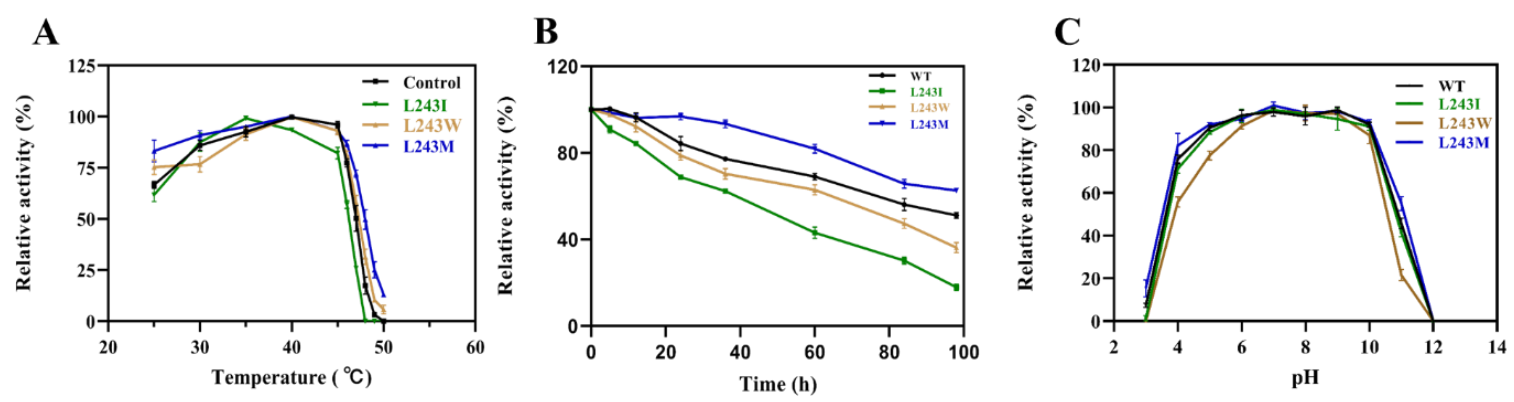

Figure 5. Biochemical characterization of $L b \mathrm{MDH}$ and its variants. (A) effect of temperature on the enzymatic activity of $L b \mathrm{MDH}$ and its variants; (B) thermostability was determined by measuring the enzymatic activity of $\mathrm{LbMDH}$ and its variants after treatment for the corresponding time at $40{ }^{\circ} \mathrm{C}$; (C) effects of $\mathrm{pH}$ stability on the enzymatic activity of $L b \mathrm{MDH}$ and its variants, assayed at different $\mathrm{pH}$ for $24 \mathrm{~h}$.

Kinetic parameters of the purified $L b \mathrm{MDH}$ and its variants were measured using different $\alpha$-HAs as the substrates (Table 3). Compared with the wild type, variant L243W showed 3.45 times lower $K_{\mathrm{m}}$ with $\mathrm{D}-\alpha$-hydroxybutyric acid, and it also showed lower $K_{\mathrm{m}}$ with D-lactic acid. However, variant L243W showed increased $K_{\mathrm{m}}$ with D-mandelic acid, D- $\alpha$-hydroxycaproic acid, and D-phenyllactic acid, while these substrates were with long side chains. Variant L243I showed lower Km and improved catalytic efficiency towards D-phenyllactic acid and D- $\alpha$-hydroxycaproic acid compared to the wild type. The preferred substrate of L243M was D-mandelic acid with improved $k_{\text {cat }} / K_{\mathrm{m}}$ of $0.05 \mathrm{~S}^{-1} \mathrm{mM}^{-1}$ compared to the wild type. However, the $k_{\text {cat }} / K m$ of the variants still not high and compared with the wild type, and all $K_{\mathrm{m}}$ values of the variants for cofactor NAD increased. These results indicated that mutations at L243 changed the size of substrate entrance channel, which could influence the substrate affinities and catalytic efficiencies.

\subsection{Structure Analysis of LbMDH and Variants}

Structure analysis of $L b \mathrm{MDH}$ and the variants was carried out to study the reason for the different specific activities and affinities towards different substrates. Molecular docking of $L b \mathrm{MDH}$ and its variants together with D-mandelic acid and cofactor NAD were carried out by Autodock vina [33]. As showed in Figure 6, residue 243 was located at the substrate entrance channel and there were no inter-molecular hydrogen bonds between residue 243 and other residues. The replacement of Leu243 
with Trp narrowed the substrate entrance channel, making the enzyme substrate entrance channel more favorable for substrates with small side chains. The L243M and L243I mutations also changed the size of entrance channel making it accessible by different substrates.

Table 3. Kinetic parameters of $L b \mathrm{MDH}$ and its variants.

\begin{tabular}{|c|c|c|c|c|c|c|}
\hline \multirow[b]{2}{*}{ Substrate } & \multicolumn{3}{|c|}{ WT } & \multicolumn{3}{|c|}{ L243M } \\
\hline & $\begin{array}{c}K m \\
(\mathrm{mM})\end{array}$ & $\begin{array}{l}k_{\text {cat }} \\
\left(\mathrm{s}^{-1}\right)\end{array}$ & $\begin{array}{c}k_{\text {cat }} / \mathrm{Km} \\
\left(\mathrm{s}^{-1} \mathrm{mM}^{-1}\right)\end{array}$ & $\begin{array}{c}K m \\
(\mathrm{mM})\end{array}$ & $\begin{array}{l}k_{c a t} \\
\left(\mathrm{~s}^{-1}\right)\end{array}$ & $\begin{array}{c}k_{\text {cat }} / K m \\
\left(\mathrm{~s}^{-1} \mathrm{mM}^{-1}\right)\end{array}$ \\
\hline D-mandelic acid & $3.71 \pm 0.031$ & $0.44 \pm 0.011$ & 0.118 & $3.09 \pm 0.196$ & $0.52 \pm 0.090$ & 0.168 \\
\hline D- $\alpha$-hydroxybutanoic acid & $31.7 \pm 0.580$ & $0.22 \pm 0.005$ & 0.007 & $25.9 \pm 0.207$ & $0.05 \pm 0.006$ & 0.002 \\
\hline D- $\alpha$-hydroxycaproic acid & $20.9 \pm 0.106$ & $0.41 \pm 0.037$ & 0.02 & $18.7 \pm 0.583$ & $0.51 \pm 0.032$ & 0.027 \\
\hline D-lactic acid & $60.4 \pm 2.934$ & $0.05 \pm 0.001$ & 0.001 & $61.7 \pm 4.535$ & $0.08 \pm 0.005$ & 0.001 \\
\hline \multirow[b]{2}{*}{ Substrate } & \multicolumn{3}{|c|}{ L243W } & \multicolumn{3}{|c|}{ L243I } \\
\hline & $\begin{array}{c}K m \\
(\mathrm{mM})\end{array}$ & $\begin{array}{l}k_{\text {cat }} \\
\left(\mathrm{s}^{-1}\right)\end{array}$ & $\begin{array}{c}k_{\text {cat }} / \mathrm{Km} \\
\left(\mathrm{s}^{-1} \mathrm{mM}^{-1}\right)\end{array}$ & $\begin{array}{c}\mathrm{Km} \\
(\mathrm{mM})\end{array}$ & $\begin{array}{l}k_{c a t} \\
\left(\mathrm{~s}^{-1}\right)\end{array}$ & $\begin{array}{c}k_{\text {cat }} / K m \\
\left(\mathrm{~s}^{-1} \mathrm{mM}^{-1}\right)\end{array}$ \\
\hline D-phenyllactic acid & $49.8 \pm 0.576$ & $0.10 \pm 0.019$ & 0.002 & $33.7 \pm 0.985$ & $0.18 \pm 0.038$ & 0.005 \\
\hline D-lactic acid & $48.2 \pm 1.339$ & $0.13 \pm 0.009$ & 0.003 & $65.3 \pm 1.805$ & $0.09 \pm 0.002$ & 0.001 \\
\hline
\end{tabular}
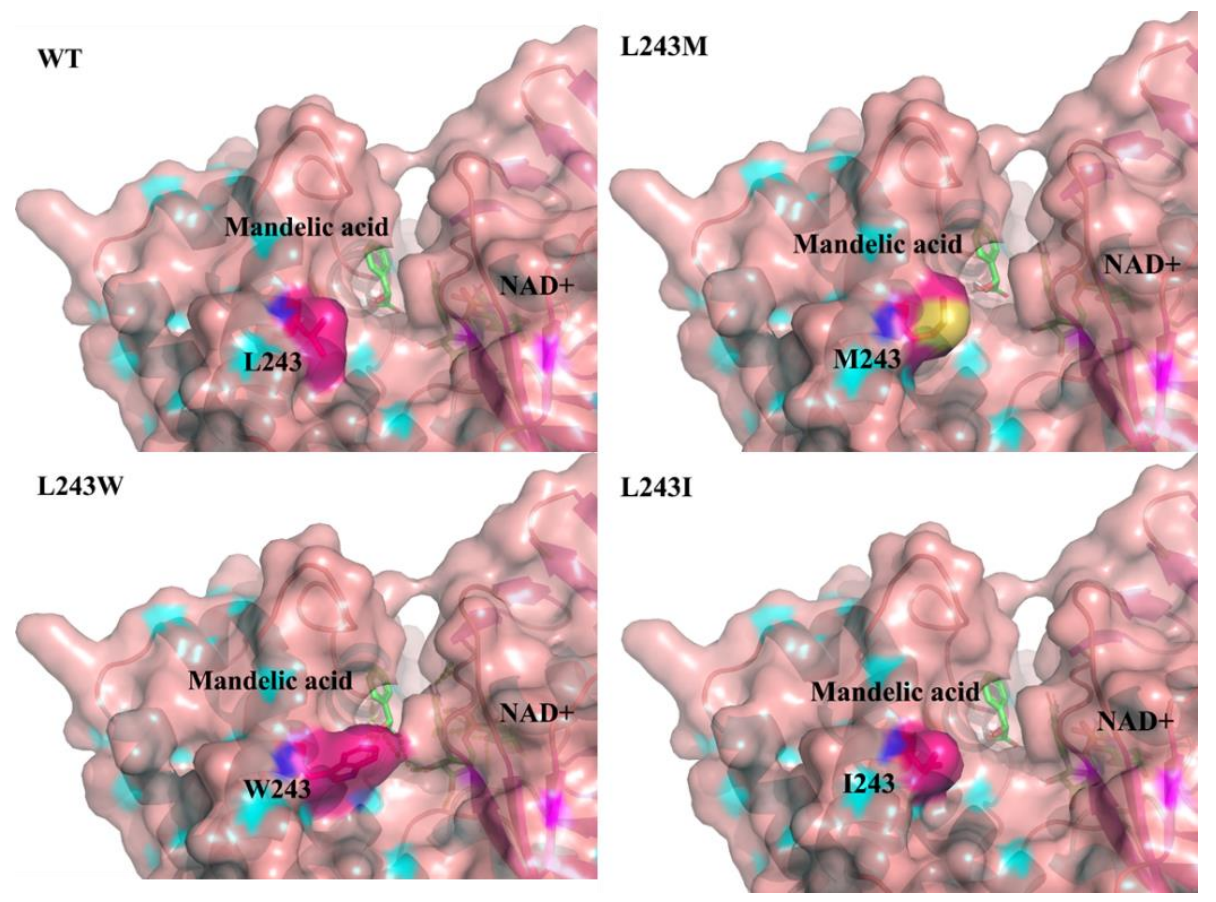

Figure 6. Structure analysis of $L b \mathrm{MDH}$ and the variants. The structures of $L b \mathrm{MDH}$ and its variants were modeled by SWISS-MODEL and displayed by PyMol. The structure was displayed with different colors: helix marked in cyan, sheet marked in magenta, loop marked in orange, ligands with the carbon backbone marked in green, and the 243th residue marked in magenta.

To further study the structural differences of $L b \mathrm{MDH}$ and its variants, molecular dynamics was performed in $298 \mathrm{~K}$ for $30 \mathrm{~ns}$ with protein complexes including enzymes and ligands. As shown in Figure S6, the total energy value of $L b \mathrm{MDH}$ and its variants with different substrates were almost the same, indicating that the mutations in residue 243 had little effect on the conformation stability of 
the protein structure [34]. We also analyzed the root mean square fluctuation (RMSF) value (shown in Figure S6), and results showed minimal differences in the engineered structure compared to the wild type, while slight differences were observed in gray shadowed regions representing the loops far from the active center (Figure S7). Through these preliminary molecular dynamics analysis, we noticed that the mutations at 243 did not directly influence the catalytic ability, probably as the 243th residue located at the substrate channel and was distant from the active center. To further explain the effect of mutation at position 243 on the enzymatic specific activities and affinities towards different substrates, further molecular dynamics targeting the dynamic of the entrance channel could be done in later research.

\subsection{Secondary Structure and Thermostability Analysis by Circular Dichroism (CD)}

To verify the proper folding of $L b \mathrm{MDH}$ and its variants, the secondary structure was determined by circular dichroism. As shown in Figure 7, the far-UV CD spectrum of the four enzymes exhibited similar absorbance from 190 to $240 \mathrm{~nm}$, with all showing positive peaks at $193 \mathrm{~nm}$ and two negative peaks at $209 \mathrm{~nm}$ and $219 \mathrm{~nm}$, suggesting correct folding of the mutants [34,35]. To further study the temperature stability of $L b \mathrm{MDH}$ and variants, we measured the melting temperature $(\mathrm{Tm})$ by monitoring their dichroic signal reduction at $220 \mathrm{~nm}$ at an elevated temperature from $20-70{ }^{\circ} \mathrm{C}$. The variant $\mathrm{L} 243 \mathrm{M}$ had a Tm value of $40.50^{\circ} \mathrm{C}$, which was $1.58^{\circ} \mathrm{C}$ higher than that of the wild type, in line with the thermo-stability essay results for variant L243M.
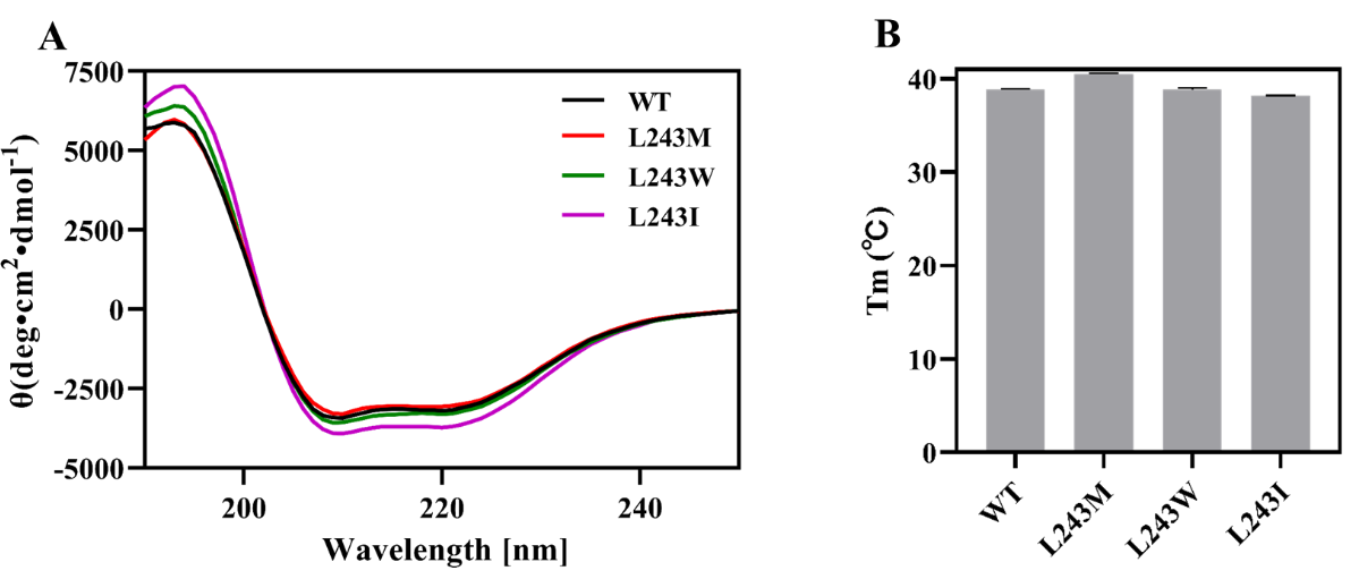

Figure 7. Secondary structure and melting temperature analysis (A) circular dichroism spectra for WT and variants; (B) the melting temperatures of $L b \mathrm{MDH}$ and its variants.

\subsection{One-Pot Biocatalytic Preparation of UAAs with a Double-Enzyme System}

As UAAs are such important chemicals, the biocatalytic preparation of UAAs would be valuable, especially for the production of aliphatic and aromatic UAAs. Thus, we designed a hydrogen-borrowing dual-enzyme cascade for the synthesis of structurally diverse range of aromatic and aliphatic UAAs from $\alpha$-HAs. Here, we used the engineered $L b \mathrm{MDH}$ together with $B c \mathrm{LeuDH}_{\mathrm{T} 45 \mathrm{M} / \mathrm{E} 116 \mathrm{~V}}$ constructed before in our lab to biosynthesize UAAs [9]. Then, the dual-enzyme cascade biocatalysis preparation was conducted in a shake flask with $0.1 \mathrm{mg} / \mathrm{mL} L b \mathrm{MDH}$ or its variants and $0.5 \mathrm{mg} / \mathrm{mL} \mathrm{BcLeuDH}{ }_{\mathrm{T} 45 \mathrm{M} / \mathrm{E} 116 \mathrm{~V}}$. For the biocatalytic preparation of L-phenylglycine, we used an L243M variant of $L b \mathrm{MDH}$, which had the highest catalytic ability towards D-mandelic acid in this study. As showed in Figure 8A, upon adding D-mandelic acid ( $150 \mathrm{mM}, 22.8 \mathrm{~g} / \mathrm{L})$ to the reaction system once, the production yield of $L b \mathrm{MDH}_{\mathrm{L} 243 \mathrm{M}}$ reached $20.7 \mathrm{~g} / \mathrm{L}$, higher than the $18.9 \mathrm{~g} / \mathrm{L}$ of using wild type and, most importantly, the production efficiency improved from $0.30 \mathrm{~g} / \mathrm{L} / \mathrm{min}$ to $0.47 \mathrm{~g} / \mathrm{L} / \mathrm{min}$. Similarly, variant $\mathrm{L} 243 \mathrm{~W}$ of $\mathrm{LbMDH}$ was used for biotransformation of D- $\alpha$-hydroxybutyric acid $(150 \mathrm{mM}, 15.6 \mathrm{~g} / \mathrm{L})$, and the results showed in Figure $8 \mathrm{~B}$ indicated that the conversion of L- $\alpha$-aminobutyric acid was close to $67 \%$, higher than $46.8 \%$ for the wild type. 

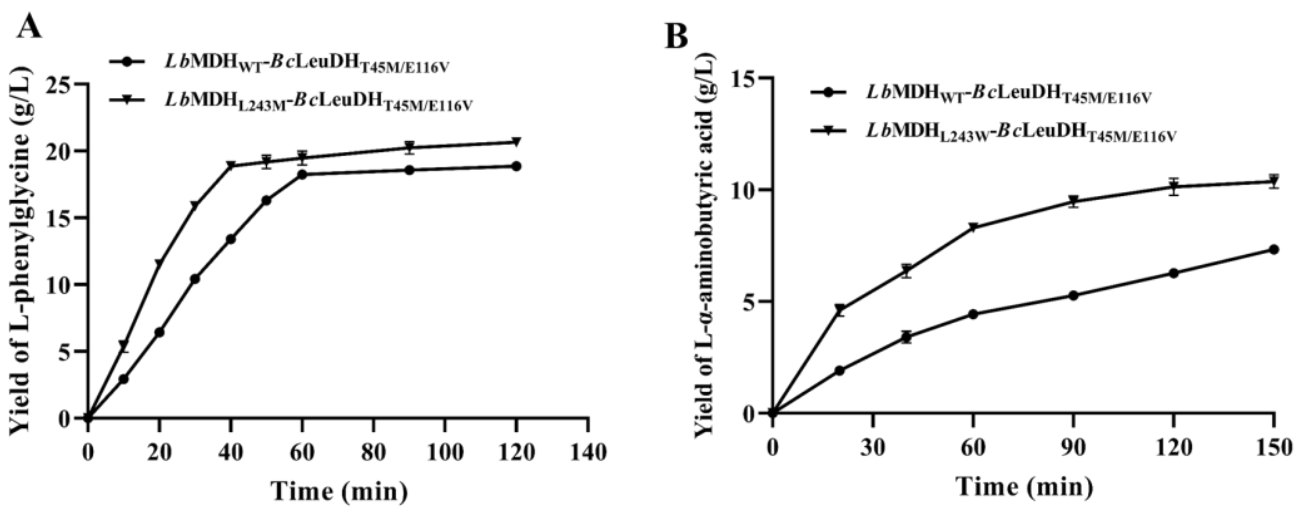

Figure 8. Biocatalytic preparation of UAAs. (A) the yield of L-phenylglycine obtained using the D-mandelic acid as substrate for the WT and L243M variant; (B) the yield of L- $\alpha$-aminobutyric acid in the hydrogen-borrowing dual-enzyme cascade for the WT and L243W variant. Error bars showed the standard deviation and data were collected from three independent experiments.

\section{Materials and Methods}

\subsection{Strains, Plasmids, and Materials}

The sequence of the D-mandelate dehydrogenases ( $L b \mathrm{MDH})$ from $L$. brevis was obtained from GenBank (Gene ID: 4413215) and synthesized by GENEWIZ Biotech Co., Ltd. (Suzhou, China). The genes encoding Ef2D2R (Protein ID EGP5414127.1), SaDlacDH (Protein ID OHS90358.1), PaDlacDH (Protein ID PTC35631.1), and Pa2D2R (Protein ID EOT12896.1) from E. faecalis, S. aureus, and P. aeruginosa were used as template. The primers used for cloning were listed in Table S1. E. coli JM109 was used as the host for gene cloning, and E. coli BL21 (DE3) was used as the host for the expression of different enzymes. The plasmid pET-28a (+) purchased from Invitrogen (Carlsbad, CA, USA) was employed as the expression vector. $2 \times$ Phanta Max Master Mix and ClonExpress II One Step Cloning Kit were purchased from Vazyme Biotech Co., Ltd. (Nanjing, China).

The restriction enzymes EcoR I and Hind III were obtained from TaKaRa (Dalian, China). All of the $\alpha$-HAs and UAAs were purchased from Sigma-Aldrich (Darmstadt, Germany) or Aladdin Reagent (Shanghai, China).

\subsection{Site-Directed and Structure Analysis of $\mathrm{LbMDH}$}

Site-directed mutagenesis of the $\mathrm{L} b \mathrm{MDH}$ gene was carried out using the whole-plasmid two-step PCR method [36], and the pET28a-LbMDH plasmid was used as the template. Site-saturation mutagenesis at position L243 was conducted by degenerate codon of NNN (N represents A, T, G or C). The primers used for the mutagenesis were listed in Table S2. All recombinant plasmids were transformed into E. coli BL21 (DE3) and sequenced by GENEWIZ Biotech Co., Ltd. (Suzhou, China). Luria-Bertani (LB) broth was used for the growth of E. coli and contained kanamycin $(50 \mu \mathrm{g} / \mathrm{mL})$ for plasmid selection.

The structure of $L b \mathrm{MDH}$ was built by homology modeling using the free online software SWISS-MODEL with D-mandelate dehydrogenase from E. faecalis (PDB entry 5X20) as the template. The docking of substrates and enzymes was done by AutoDock, and the structures of the wild-type $L b \mathrm{MDH}$ and its variants were performed by PyMol software. All MD simulations were performed using GROMACS 2018.4 [37] software at 298 K. Amber ff99SB, and GAFF force fields were chosen to describe the proteins and ligands [38], respectively. The MD simulation was performed in several steps, including energy minimization, heating, density equilibration, and 30-ns production MD, with a time step of $2 \mathrm{fs}$. 


\subsection{Expression and Purification of LbMDH and Its Variants}

All the recombinant proteins were expressed by E. coli BL21 (DE3) with an N-terminal 6-His tag. Single colonies of these recombinant strains were inoculated into $10 \mathrm{~mL}$ LB medium containing $50 \mu \mathrm{g} / \mathrm{mL}$ kanamycin, and cultured at $37^{\circ} \mathrm{C}$ with shaking at $180 \mathrm{rpm}$ for $10-12 \mathrm{~h}$ as seed liquid. Then, the cells were transformed into $50 \mathrm{~mL} \mathrm{LB}$ medium with $1 \%$ inoculation as well as $50 \mu \mathrm{g} / \mathrm{mL}$ kanamycin and cultured for about $2 \mathrm{~h}$ until the OD600 reached 0.6-0.8. Isopropyl B-D-1-thiogalactopyranoside was added to a final concentration of $0.5 \mathrm{mM}$ to induce the protein expression at $16^{\circ} \mathrm{C}$ for $10 \mathrm{~h}$. Then, the cell was harvested by centrifugation at $8,000 \times \mathrm{q}$ for $10 \mathrm{~min}$.

After washed twice with $0.2 \mathrm{M}$ phosphate buffer ( $\mathrm{pH} 7.0$ ), the cells were suspended again to be sonicated under the ice bath. The cell disruption was centrifuged at $12,000 \times \mathrm{g}$ for $20 \mathrm{~min}$ at $4{ }^{\circ} \mathrm{C}$ to obtain the crude enzyme solution. These solutions were used to purification using $\mathrm{Ni}^{2+}$-affinity chromatography on the ÄKTA purifier system by HisTrap column from General Electric Company (Boston, MA, USA). Then, SDS-PAGE analysis and the Bradford protein assay kit were used to check and determine the concentration of the purified enzymes.

\subsection{Enzyme Activity Assays}

As $\mathrm{Lb} \mathrm{MDH}$ uses nicotinamide adenine dinucleotide $\left(\mathrm{NAD}^{+}\right)$as the coenzyme, the enzyme activities of $L b \mathrm{MDH}$ and its variants were determined by measuring the change of UV absorbance at $340 \mathrm{~nm}$. The unit of enzyme activity was defined as $1 \mu \mathrm{mol}$ of $\operatorname{NAD}\left(\varepsilon=6.22 \mathrm{mM}^{-1} \mathrm{~cm}^{-1}\right)$ increased per min. The assay mixture contained $6.5 \mathrm{mM} \mathrm{D}$ - $\alpha$-hydroxy acid and $1.5 \mathrm{mM}$ NAD in $200 \mathrm{mM}$ $\mathrm{Na}_{2} \mathrm{HPO}_{4}-\mathrm{NaOH}$ buffer, $\mathrm{pH} 10.5$, and the reaction was started by the addition of limiting amounts of $L b \mathrm{MDH}$. The initial rate of the purified $L b \mathrm{MDH}$ and $B c L e u D H$ was determined by measuring the production titer of L-phenylglycine in $30 \mathrm{~min}$.

The optimal temperatures for $L b \mathrm{MDH}$ and its variants were determined at $\mathrm{pH} 10.5$ with the temperatures ranging from $25-50{ }^{\circ} \mathrm{C}$. The optimal $\mathrm{pH}$ was measured by assaying the enzyme activity using different $\mathrm{pH}$ range buffers as follows: citric acid sodium citrate buffer ( $\mathrm{pH} 3.0-6.0,200 \mathrm{mM})$, potassium phosphate buffer $(\mathrm{pH}$ 6.0-8.0, $200 \mathrm{mM}), \mathrm{NH}_{3} \cdot \mathrm{H}_{2} \mathrm{O}-\mathrm{NH}_{4} \mathrm{Cl}$ buffer $(\mathrm{pH} 8.0-10.0,200 \mathrm{mM})$, and $\mathrm{Na}_{2} \mathrm{HPO}_{4}-\mathrm{NaOH}$ buffer (pH 10.0-12.0, $100 \mathrm{mM}$ ).

The thermal stability of the enzymes was monitored by enzyme incubation in PBS buffer $(50 \mathrm{mM}$, $\mathrm{pH} 7.4)$ at $30^{\circ} \mathrm{C}$ and $40^{\circ} \mathrm{C}$ for different times. The residual enzyme activities after incubation were measured at $30^{\circ} \mathrm{C}$ in $\mathrm{Na}_{2} \mathrm{HPO}_{4}-\mathrm{NaOH}$ buffer $(\mathrm{pH} \mathrm{10.5,200} \mathrm{mM})$. The half-lives of thermal inactivation $\left(t_{1 / 2}\right)$ of the purified enzymes at $40^{\circ} \mathrm{C}$ were calculated using the equation $t_{1 / 2}=\ln 2 / \mathrm{k}$, and the first-order rate constant, $\mathrm{k}$, was obtained from the slope of a semilogarithmic plot of incubation time versus residual activity. Additionally, to determine the $\mathrm{pH}$ stability of $\mathrm{LbMDH}$ and its variants, the purified enzymes were incubated in different buffers described above for $12 \mathrm{~h}$ at $4{ }^{\circ} \mathrm{C}$. The residual enzyme activity in different $\mathrm{pH}$ was measured using the method described for the thermal stability assay.

\subsection{Determination of Kinetic Characteristics}

The Michaelis constant $(\mathrm{Km})$ and maximal velocity ( Vmax) of the wild type $\mathrm{LbMDH}$ and its mutations were measured in $200 \mathrm{mM} \mathrm{Na}_{2} \mathrm{HPO}_{4}-\mathrm{NaOH}$ buffer $(\mathrm{pH} 10.5)$ at $30^{\circ} \mathrm{C}$ under the condition of one limiting substrate ( $\alpha$-HAs or NAD). The Km values for $\alpha$-HAs were determined by changing the concentration in the range of $0.12-22 \mathrm{mM}$, and the $\mathrm{Km}$ for NAD was measured with the concentration vary from 0.04 to $2 \mathrm{mM}$. Then, the $\mathrm{Km}$ and $V$ max of all substrates were obtained through the Lineweaver Burk method using the program GraphPad Prism 8. The $k_{\text {cat }}$ was calculated through the following equation $k_{c a t}=\operatorname{Vmax} /(E)$, where $(E)$ represents the molar concentration of the enzymes.

\subsection{Circular Dichroism for Structure Analysis and Thermal Melts}

Circular dichroism (CD) analysis of LbMDH and L243 mutations was conducted in a J-1700 spectrometer (Jasco, Tokyo, Japan) using a 0.1-cm path-length quartz cuvette. The enzyme samples 
were diluted to $0.1 \mathrm{mg} / \mathrm{mL}$ in ultrapure water. The far-UV CD spectra were recorded in the range from 190 to $240 \mathrm{~nm}$ with a scan speed of $50 \mathrm{~nm} / \mathrm{min}$. The melting temperature (Tm) was determined at a rate of $3{ }^{\circ} \mathrm{C} / \mathrm{min}$ between $20^{\circ} \mathrm{C}$ to $70^{\circ} \mathrm{C}$ while measuring $\mathrm{CD}$ at $222 \mathrm{~nm}$. The Tm of the enzymes were obtained from the first derivative of the thermal melt curves using the program GraphPad Prism 8.

\subsection{Biocatalytic Preparation of UAAs with a Dual-Enzyme Hydrogen-Borrowing Cascade}

The biotransformation system contained $0.9 \mathrm{M} \mathrm{NH}_{3} \cdot \mathrm{H}_{2} \mathrm{O}-\mathrm{NH}_{4} \mathrm{Cl}$ buffer ( $\mathrm{pH}$ 9.5), $5 \mathrm{mM} \mathrm{NAD}^{+}$, $0.1 \mathrm{mg} / \mathrm{mL} \mathrm{LbMDH}, 0.3 \mathrm{mg} / \mathrm{mL} B c \mathrm{LeuDH}_{\mathrm{T} 45 \mathrm{M} / \mathrm{E} 116 \mathrm{~V}}, 150 \mathrm{mM} \mathrm{D}-\alpha-\mathrm{HAs}$. Sample aliquots were withdrawn from the reaction mixture to detect the concentrations of substrates and products. The substrates D- $\alpha$-HAs and the intermediate product $\alpha$-keto acids were detected on Agilent LC1260 HPLC system using an Aminex HPX-87H analysis column (Bio-Rad, $300 \times 7.8 \mathrm{~mm}$ ) with $5 \mathrm{mM} \mathrm{H}_{2} \mathrm{SO}_{4}$ as the mobile phase, the UV detector wavelength was set to $254 \mathrm{~nm}$, and the flow rate was $0.5 \mathrm{~mL} / \mathrm{min}$ at $35{ }^{\circ} \mathrm{C}$. The $\alpha$-amino acids were detected by the HPLC system using the method described by Zhang and Bartolomeo $[39,40]$.

\section{Conclusions}

In summary, we designed a hydrogen-borrowing dual-enzyme cascade for the synthesis of structurally diverse range of aromatic and aliphatic UAAs from D- $\alpha$-HAs. Firstly, we screened a D-mandelate dehydrogenase from L. brevis to catalyze D- $\alpha$-HAs to corresponding $\alpha$-keto acids with higher enzyme activities. However, the activity for aliphatic substrates were relatively low. To improve the enzymatic activities towards aliphatic substrates, we rationally engineered the substrate entrance tunnel of $L b \mathrm{MDH}$ with the help of sequence and structure analysis. The variant L243W was obtained with higher activity towards D- $\alpha$-hydroxybutyric acid and decreased activity towards D-mandelic acid. Then, site-saturation mutagenesis at L243 was performed. Three important variants with higher enzyme activities and better substrate affinities towards different substrates (L243M, L243W, L243I) were identified. Among the variants, only variant L243M showed improved thermostability compared to the wild type. Structural analysis of these variants showed that mutations of the residues at the entrance of substrate channel of $L b \mathrm{MDH}$ significantly affected the size of the channel, thus influencing the enzyme affinities for different substrates. Finally, a hydrogen-borrowing dual-enzyme cascade was

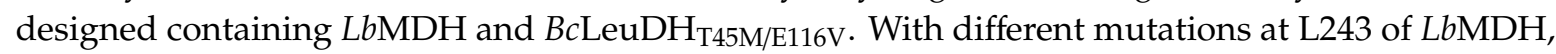
the production of different UAAs greatly improved. However, compared with other reports that use racemic mandelic acid as a substrate to synthesize L-phenylglycine, our conversion towards mandelic acid was not that high. Resch et al. have designed a redox-neutral reaction cascade and achieved $94 \%$ conversion for L-phenylglycine from racemic mandelic acid [20], and Fan et al. also report a three-enzyme cascade reaction which can convert $0.2 \mathrm{M}$ rac-mandelic acid to L-phenylglycine with $96.4 \%$ conversion rate [22] — whereas, we are the first one to report the biocatalytic preparation of two types of important UAAs including aromatic and aliphatic UAAs from $\alpha$-HAs using a hydrogen-borrowing dual-enzyme cascade.

Supplementary Materials: The following are available online at http://www.mdpi.com/2073-4344/10/12/1470/s1, Figure S1: SDS-PAGE analysis of the expression of D-hydroxy acid dehydrogenases from different sources, Figure S2: Optimum $\mathrm{pH}$ of D-hydroxy acid dehydrogenase from different sources, Figure S3: Multiple-sequence alignment of D-mandelate dehydrogenase with other D-hydroxy acid dehydrogenase from Lactobacillus harbinensi and E. faecium by the help of software Clustal X and Espript 3, Figure S4: Optimum pH of variants of $L b \mathrm{MDH}$, Figure S5: The exponential fitting curves of the data points of thermostability analysis, Figure S6: Structure analysis of $L b \mathrm{MDH}$ and the variants by MD simulation, Figure S7: Structure analysis of $L b \mathrm{MDH}$ and the variants, Table S1: Primers used for cloning of D-hydroxy acid dehydrogenase, Table S1: Primers used for site-directed and saturated mutagenesis.

Author Contributions: Conceptualization, F.L. and J.Z.; methodology, F.L.; software, F.L. and J.Z.; validation, F.L., X.Z., and Z.R.; formal analysis, F.L.; investigation, F.L. and J.Z.; resources, M.X., T.Y., M.S., X.Z., and Z.R.; data curation, F.L. and J.Z.; writing-original draft preparation, F.L.; writing-review and editing, F.L., M.X., T.Y., M.S., X.Z., and Z.R.; visualization, X.Z.; supervision, F.L., M.X., T.Y., and M.S.; project administration, F.L., 
X.Z., and Z.R.; funding acquisition, X.Z. and Z.R. All authors have read and agreed to the published version of the manuscript.

Funding: This work was supported by the National Key Research and Development Program of China, (No. 2020YFA0908300), National Natural Science Foundation of China (No. 32071470), Key Research and Development Program of Ningxia Hui Autonomous Region, (No. 2019BCH01002, 2020BFH01001,), Key Research and Development Project of Shandong Province, China (No. 2019JZZY020605), the Project Supported by the Foundation of State Key Laboratory of Biobased Material and Green Papermaking, Qilu University of Technology, Shandong Academy of Sciences (No. KF201907), Program of the Key Laboratory of Industrial Biotechnology, Ministry of Education, China (No. KLIB-KF202009), National First-Class Discipline Program of Light Industry Technology and Engineering, (LITE2018-06), the Project Funded by the Priority Academic Program Development of Jiangsu Higher Education Institutions, Top-Notch Academic Programs Project of Jiangsu Higher Education Institutions.

Conflicts of Interest: The authors declare no conflict of interest.

\section{References}

1. Narancic, T.; Almahboub, S.A.; O'Connor, K.E. Unnatural amino acids: Production and biotechnological potential. World J. Microbiol. Biotechnol. 2019, 35, 67. [CrossRef]

2. Kim, J.Y.; Lee, Y.A.; Wittmann, C.; Park, J.B. Production of non-proteinogenic amino acids from $\alpha$-keto acid precursors with recombinant Corynebacterium glutamicum. Biotechnol. Bioeng. 2013, 110, 2846-2855. [CrossRef]

3. Cui, Z.; Mureev, S.; Polinkovsky, M.E.; Tnimov, Z.; Guo, Z.; Durek, T.; Jones, A.; Alexandrov, K. Combining Sense and Nonsense Codon Reassignment for Site-Selective Protein Modification with Unnatural Amino Acids. ACS Synth. Biol. 2017, 6, 535-544. [CrossRef]

4. Blaskovich, M.A. Unusual Amino Acids in Medicinal Chemistry. J. Med. Chem. 2016, 59, 10807-10836. [CrossRef] [PubMed]

5. He, Y.; He, X. Molecular design and genetic optimization of antimicrobial peptides containing unnatural amino acids against antibiotic-resistant bacterial infections. Biopolymers 2016, 106, 746-756. [CrossRef] [PubMed]

6. Maluch, I.; Czarna, J.; Drag, M. Applications of Unnatural Amino Acids in Protease Probes. Chem. Asian J. 2019, 14, 4103-4113. [CrossRef] [PubMed]

7. Zerfas, B.L.; Coleman, R.A.; Salazar-Chaparro, A.F.; Macatangay, N.J.; Trader, D.J. Fluorescent Probes with Unnatural Amino Acids to Monitor Proteasome Activity in Real-Time. ACS Chem. Biol. 2020, 15, 2588-2596. [CrossRef]

8. Soth, M.; Hermann, J.C.; Yee, C.; Alam, M.; Barnett, J.W.; Berry, P.; Browner, M.F.; Frank, K.; Frauchiger, S.; Harris, S.; et al. 3-Amido pyrrolopyrazine JAK kinase inhibitors: Development of a JAK3 vs JAK1 selective inhibitor and evaluation in cellular and in vivo models. J. Med. Chem. 2013, 56, 345-356. [CrossRef]

9. Zhou, J.; Wang, Y.; Chen, J.; Xu, M.; Yang, T.; Zheng, J.; Zhang, X.; Rao, Z. Rational Engineering of Bacillus cereus Leucine Dehydrogenase Towards $\alpha$-keto Acid Reduction for Improving Unnatural Amino Acid Production. Biotechnol. J. 2019, 14, e1800253. [CrossRef]

10. Al Toma, R.S.; Brieke, C.; Cryle, M.J.; Süssmuth, R.D. Structural aspects of phenylglycines, their biosynthesis and occurrence in peptide natural products. Nat. Prod. Rep. 2015, 32, 1207-1235. [CrossRef]

11. Langen, L.M.V.; Rantwijk, F.V.; Švedas, V.K.; Sheldon, R.A.J.T.A. Penicillin acylase-catalyzed peptide synthesis: A chemo-enzymatic route to stereoisomers of 3,6-diphenylpiperazine-2,5-dione. Tetrahedron Asymmetry 2000, 11, 1077-1083. [CrossRef]

12. Weber, N.; Hatsch, A.; Labagnere, L.; Heider, H. Production of (S)-2-aminobutyric acid and (S)-2-aminobutanol in Saccharomyces cerevisiae. Microb. Cell Factories 2017, 16, 51. [CrossRef] [PubMed]

13. Zhu, L.; Tao, R.; Wang, Y.; Jiang, Y.; Lin, X.; Yang, Y.; Zheng, H.; Jiang, W.; Yang, S. Removal of L-alanine from the production of L-2-aminobutyric acid by introduction of alanine racemase and D-amino acid oxidase. Appl. Microbiol. Biotechnol. 2011, 90, 903-910. [CrossRef] [PubMed]

14. Yadav, V.N.; Comotti, A.; Sozzani, P.; Bracco, S.; Bonge-Hansen, T.; Hennum, M.; Görbitz, C.H. Microporous Molecular Materials from Dipeptides Containing Non-proteinogenic Residues. Angew. Chem. (Int. Ed. Engl.) 2015, 54, 15684-15688. [CrossRef] [PubMed]

15. Xu, J.M.; Li, J.Q.; Zhang, B.; Liu, Z.Q.; Zheng, Y.G. Fermentative production of the unnatural amino acid L-2-aminobutyric acid based on metabolic engineering. Microb. Cell Factories 2019, 18, 43. [CrossRef] 
16. Song, W.; Wang, J.H.; Wu, J.; Liu, J.; Chen, X.L.; Liu, L.M. Asymmetric assembly of high-value $\alpha$-functionalized organic acids using a biocatalytic chiral-group-resetting process. Nat. Commun. 2018, 9, 3818. [CrossRef]

17. Schrittwieser, J.H.; Velikogne, S.; Hall, M.; Kroutil, W. Artificial Biocatalytic Linear Cascades for Preparation of Organic Molecules. Chem. Rev. 2018, 118, 270-348. [CrossRef]

18. Liu, Z.; Yu, L.; Zhou, L.; Zhou, Z. One-Pot Biosynthesis of 1-Aspartate from Maleate via an Engineered Strain Containing a Dual-Enzyme System. Appl. Environ. Microbiol. 2019, 85. [CrossRef]

19. Wu, S.; Zhou, Y.; Wang, T.; Too, H.P.; Wang, D.I.; Li, Z. Highly regio- and enantioselective multiple oxy- and amino-functionalizations of alkenes by modular cascade biocatalysis. Nat. Commun. 2016, 7, 11917. [CrossRef]

20. Resch, V.; Fabian, W.M.F.; Kroutil, W.J.A.S. Deracemisation of Mandelic Acid to Optically Pure Non-Natural L-Phenylglycine via a Redox-Neutral Biocatalytic Cascade. Adv. Synth. Catal. 2010, 352, 993-997. [CrossRef]

21. Böhmer, W.; Knaus, T.; Mutti, F.G. Hydrogen-Borrowing Alcohol Bioamination with Coimmobilized Dehydrogenases. ChemCatChem 2018, 10, 731-735. [CrossRef] [PubMed]

22. Fan, C.W.; Xu, G.C.; Ma, B.D.; Bai, Y.P.; Zhang, J.; Xu, J.H. A novel D-mandelate dehydrogenase used in three-enzyme cascade reaction for highly efficient synthesis of non-natural chiral amino acids. J. Biotechnol. 2015, 195, 67-71. [CrossRef] [PubMed]

23. Tang, C.D.; Shi, H.L.; Jia, Y.Y.; Li, X.; Wang, L.F.; Xu, J.H.; Yao, L.G.; Kan, Y.C. High level and enantioselective production of L-phenylglycine from racemic mandelic acid by engineered Escherichia coli using response surface methodology. Enzym. Microb. Technol. 2020, 136, 109513. [CrossRef] [PubMed]

24. Arnold, F.H. Directed Evolution: Bringing New Chemistry to Life. Angew. Chem. (Int. Ed. Engl.) 2018, 57, 4143-4148. [CrossRef]

25. Almhjell, P.J.; Boville, C.E.; Arnold, F.H. Engineering enzymes for noncanonical amino acid synthesis. Chem. Soc. Rev. 2018, 47, 8980-8997. [CrossRef]

26. Klaus, M.; Grininger, M. Engineering strategies for rational polyketide synthase design. Nat. Prod. Rep. 2018, 35, 1070-1081. [CrossRef]

27. Kokkonen, P.; Bednar, D.; Pinto, G.; Prokop, Z.; Damborsky, J. Engineering enzyme access tunnels. Biotechnol. Adv. 2019, 37, 107386. [CrossRef]

28. Bao, L.; Li, J.J.; Jia, C.; Li, M.; Lu, X. Structure-oriented substrate specificity engineering of aldehyde-deformylating oxygenase towards aldehydes carbon chain length. Biotechnol. Biofuels 2016, 9, 185. [CrossRef]

29. Liu, Q.; Zhou, J.; Yang, T.; Zhang, X.; Xu, M.; Rao, Z. Efficient biosynthesis of L-phenylglycine by an engineered Escherichia coli with a tunable multi-enzyme-coordinate expression system. Appl. Microbiol. Biotechnol. 2018, 102, 2129-2141. [CrossRef]

30. Miyanaga, A.; Fujisawa, S.; Furukawa, N.; Arai, K.; Nakajima, M.; Taguchi, H. The crystal structure of D-mandelate dehydrogenase reveals its distinct substrate and coenzyme recognition mechanisms from those of 2-ketopantoate reductase. Biochem. Biophys. Res. Commun. 2013, 439, 109-114. [CrossRef]

31. Furukawa, N.; Miyanaga, A.; Nakajima, M.; Taguchi, H. The ternary complex structure of d-mandelate dehydrogenase with NADH and anilino(oxo)acetate. Biochem. Biophys. Res. Commun. 2017, 486, 665-670. [CrossRef] [PubMed]

32. Enugala, T.R.; Corbella, M.; Kamerlin, S.C.L.; Widersten, M.J.A.C. The Role of Substrate-Coenzyme Crosstalk in Determining Turnover Rates in Rhodococcus ruber Alcohol Dehydrogenase. ACS Catal. 2020, 10, 9115-9128. [CrossRef]

33. Zhu, X.; Shin, W.H.; Kim, H.; Kihara, D. Combined Approach of Patch-Surfer and PL-PatchSurfer for Protein-Ligand Binding Prediction in CSAR 2013 and 2014. J. Chem. Inf. Modeling 2016, 56, 1088-1099. [CrossRef] [PubMed]

34. Li, Q.; Jiang, T.; Liu, R.; Feng, X.; Li, C. Tuning the $\mathrm{pH}$ profile of $\beta$-glucuronidase by rational site-directed mutagenesis for efficient transformation of glycyrrhizin. Appl. Microbiol. Biotechnol. 2019, 103, 4813-4823. [CrossRef] [PubMed]

35. Chmelova, K.; Sebestova, E.; Liskova, V.; Beier, A.; Bednar, D.; Prokop, Z.; Chaloupkova, R.; Damborsky, J. A Haloalkane Dehalogenase from Saccharomonospora viridis Strain DSM 43017, a Compost Bacterium with Unusual Catalytic Residues, Unique (S)-Enantiopreference, and High Thermostability. Appl. Environ. Microbiol. 2020, 86, e02820-19. [CrossRef] [PubMed] 
36. Sanchis, J.; Fernández, L.; Carballeira, J.D.; Drone, J.; Gumulya, Y.; Höbenreich, H.; Kahakeaw, D.; Kille, S.; Lohmer, R.; Peyralans, J.J.; et al. Improved PCR method for the creation of saturation mutagenesis libraries in directed evolution: Application to difficult-to-amplify templates. Appl. Microbiol. Biotechnol. 2008, 81, 387-397. [CrossRef] [PubMed]

37. Szilárd, P.; Abraham, M.J.; Kutzner, C.; Hess, B.; Lindahl, E. Tackling Exascale Software Challenges in Molecular Dynamics Simulations with GROMACS. arxiv 2014, arXiv:1506.00716.

38. Wang, J.; Cieplak, P.; Kollman, P.A. How well does a restrained electrostatic potential (RESP) model perform in calculating conformational energies of organic and biological molecules? Comput. Chem. 2000, 21, 1049-1074. [CrossRef]

39. Bartolomeo, M.P.; Maisano, F. Validation of a reversed-phase HPLC method for quantitative amino acid analysis. J. Biomol. Tech. JBT 2006, 17, 131-137.

40. Zhang, T.; Zhang, R.; Xu, M.; Zhang, X.; Yang, T.; Liu, F.; Yang, S.; Rao, Z.J.P.B. Glu56Ser mutation improves the enzymatic activity and catalytic stability of Bacillus subtilis L-aspartate $\alpha$-decarboxylase for an efficient $\beta$-alanine production. Process Biochem. 2018, 70, 117-123. [CrossRef]

Publisher's Note: MDPI stays neutral with regard to jurisdictional claims in published maps and institutional affiliations.

(C) 2020 by the authors. Licensee MDPI, Basel, Switzerland. This article is an open access article distributed under the terms and conditions of the Creative Commons Attribution (CC BY) license (http://creativecommons.org/licenses/by/4.0/). 